\title{
Why Are Early Career Family Physicians Driving Increases in Buprenorphine Prescribing?
}

\author{
Joshua St. Louis, MD, MPH, AAHIVS, and Nicholas Weida, MD
}

(J Am Board Fam Med 2020;33:4-6.)

The opioid crisis in the United States has reached epidemic proportions. The most recent data from the National Center for Health Statistics show that overdose deaths continue to increase drastically, from 8050 in 1999 to 70,237 in $2017 .{ }^{1}$ Medicationassisted treatment with either methadone or buprenorphine has been shown in numerous highquality trials to decrease mortality, largely due to a significant reduction in fatal overdose. ${ }^{2,3}$ Despite these clear patient-centered benefits, only $10.6 \%$ of patients with opioid use disorder are on medication-assisted treatment. ${ }^{4}$ Family physicians are solidly positioned to provide this treatment due to their broad scope of care and geographic distribution across the country. Using data from the American Board of Family Medicine, Peterson et $\mathrm{al}^{5}$ show that while buprenorphine prescribing by family physicians increased significantly from 2016 to 2018, that increase was disproportionately driven by early-career physicians with essentially no change in prescribing practices by mid- and latecareer family physicians.

The implications of these findings are broad. Peterson and his colleagues ${ }^{5}$ found that the proportion of early career family physicians prescribing buprenorphine increased from $7.1 \%$ in 2016 to $13.1 \%$ in 2018 , while the intention to prescribe buprenorphine among American Board of Family Medicine certification candidates similarly in-

Funding: none.

Conflict of interest: none declared.

Corresponding author: Joshua St. Louis, MD, MPH, AAHIVS, Lawrence Family Medicine Residency, 34 Haverhill Street, Lawrence, MA 01840 (E-mail: joshua. stlouis@glfhc.org).

\section{See Related Article on Page 7.}

creased from $14.8 \%$ to $18.7 \%$. Although these increases in prescribing practices inspire optimism, there is much work to be done. Family Medicine still lags far behind Psychiatry in terms of the percentage of clinicians with Drug Enforcement Administration (DEA)-X waivers (16.2\% of psychiatrists compared with $3.6 \%$ of family physicians in $2015)^{6}$ and the sheer numbers of patients who remain without access to evidence-based treatment is unacceptably high. In our experience, the dramatic increase in overdose deaths, especially in many of the communities where family physicians are trained, has made learning to prescribe buprenorphine imperative. Few primary care interventions boast the morbidity and mortality benefits of buprenorphine and its impact on our patients and their families is tangible. However, while increasing numbers of medical student graduates are looking for substance use disorder training, one need not look far to find examples of primary care residency programs where such an approach is not considered the norm and stigma around caring for patients with substance use disorders remains rampant. $^{6}$

So what can be done to create a more robust training environment? The authors' preparedness to provide buprenorphine was a direct result of training in residency programs where the opioid crisis was visible and the approach to treatment and training was urgent. This was augmented by training in residencies that contained 1) a mature addiction medicine curriculum, 2) a robust community of preceptors who prescribed buprenorphine, and 3) completion of the requirements to be eligible for a DEA-X waiver on graduation. Family Medicine residencies in Massachusetts have now made the decision to mandate DEA-X waiver training for their residents. We believe that a national mandate, 
Table 1. Resources for Learning to Prescribe Buprenorphine

\begin{tabular}{|c|c|c|}
\hline Resource & Location & Description \\
\hline DEA-X DATA Waiver Training & $\begin{array}{l}\text { https://www.asam.org/education/live-online- } \\
\text { cme/waiver-training }\end{array}$ & $\begin{array}{l}\text { Free courses to complete the } \\
\text { requirements to be able to } \\
\text { prescribe buprenorphine. }\end{array}$ \\
\hline $\begin{array}{l}\text { ASAM Fundamentals of Addiction } \\
\text { Medicine } 40 \text { Hour CME } \\
\text { Course }\end{array}$ & $\begin{array}{l}\text { https://elearning.asam.org/products/the- } \\
\text { asam-fundamentals-of-addiction- } \\
\text { medicine-40-hour-cme-program-online }\end{array}$ & $\begin{array}{l}\text { Online program aimed at } \\
\text { primary care and other } \\
\text { clinicians to empower } \\
\text { them to identify, treat, } \\
\text { and/or refer patients at } \\
\text { risk for or with addiction. }\end{array}$ \\
\hline $\begin{array}{l}\text { Fundamentals of Addiction } \\
\text { Medicine ECHO Series }\end{array}$ & $\begin{array}{l}\text { https://www.asam.org/education/live-online- } \\
\text { cme/fundamentals-program/fame-teleecho }\end{array}$ & $\begin{array}{l}\text { Interactive 16-week video } \\
\text { conference series for } \\
\text { clinicians that addresses } \\
\text { topics in the field of } \\
\text { addiction medicine and } \\
\text { reviews patient cases. }\end{array}$ \\
\hline $\begin{array}{l}\text { Integrating Buprenorphine } \\
\text { Treatment for Opioid Use } \\
\text { Disorder in Primary Care }\end{array}$ & $\begin{array}{l}\text { http://cahpp.org/wp-content/uploads/2017/ } \\
\text { 06/Buprenorphine-Implementation- } \\
\text { Manual-for-Primary-Care-Settings-.pdf }\end{array}$ & $\begin{array}{l}\text { Toolkit developed by a } \\
\text { multi-university } \\
\text { collaborative to provide } \\
\text { resources and support for } \\
\text { clinicians starting an } \\
\text { outpatient buprenorphine } \\
\text { treatment program. }\end{array}$ \\
\hline $\begin{array}{l}\text { Project SHOUT (Support for } \\
\text { Hospital Opioid Use Disorder } \\
\text { Treatment) }\end{array}$ & https://www.projectshout.org/ & $\begin{array}{l}\text { Guidelines, toolkits, and } \\
\text { webinars to support } \\
\text { clinicians treating } \\
\text { substance use disorders (in } \\
\text { particular OUD) in } \\
\text { hospitalized adults. }\end{array}$ \\
\hline
\end{tabular}

ASAM, American Society of Addiction Medicine; CME, Continuing Medical Education; DATA, Drug Addiction Treatment Act; DEA, Drug Enforcement Association; ECHO, Extension for Community Healthcare Outcomes; OUD, Opioid Use Disorder; SHOUT, Support for Hospital Opioid Use Disorder Treatment.

From: Bositis, CM, St. Louis, J. HIV and substance use disorder: role of the HIV physician. Infect Dis Clin N Am 2019;33:835-55.

potentially via the Accreditation Council for Graduate Medical Education (ACGME), would be appropriate to dramatically increase the number of graduating residents in primary care specialties (including Family Medicine, Internal Medicine, and Pediatrics) who are waivered to prescribe buprenorphine. Mandating DEA-X waiver training in the residency program where the authors currently work had the effect of significantly increasing the number of physicians prescribing buprenorphine 3 years after graduating from residency. With this in mind, we believe that mandating DEA-X waiver training will increase the number of buprenorphine prescribers and save lives; it is that simple.

While the increase in prescribing patterns of early career physicians seen by Peterson et $\mathrm{al}^{5}$ is encouraging, there has been no increase in buprenorphine prescribing among mid- and late-career physicians. With the dramatic rise in overdose deaths and the national distribution of opioid use disorder, why are these family physicians not learning to prescribe buprenorphine? Although stigma certainly plays a role, a number of logistic hurdles face mid- and late-career physicians becoming able to prescribe buprenorphine. First, the DEA mandates that all buprenorphine prescribers complete an 8 -hour waiver training course. ${ }^{8}$ This course is burdensome for practicing clinicians to complete. Few other medicines (certainly none of the prescription opioids that precipitated this crisis) approved by the Federal Drug Administration (FDA) are burdened by such logistic barriers. A national movement to " $X$ the $X$ waiver" is underway that seeks to remove this stringent prescribing regulation. ${ }^{9}$

Once clinicians complete their waiver training, they still need to learn how to manage the care of patients with opioid use disorder. Previous studies have shown that including comprehensive training in residency improves comfort in caring for substance use disorders, ${ }^{10}$ but how to increase prescribing among mid- and late-career clinicians is less clear. Innovative programs such as the American Society of Addiction Medicine's ECHO 
course, a teleconferenced series of lectures and case reviews, are an excellent way to reach clinicians who may be isolated from supportive specialist colleagues or advanced training programs. ${ }^{11}$ Table 1 includes a number of resources that mid- and latecareer family physicians may access to learn how to manage the care of patients with opioid use disorder.

Further increasing buprenorphine prescribing by early-career as well as mid-and late-career family physicians are not independent of one another. The authors of this commentary personally benefited from both mandatory DEA-X waiver training as well as mentorship and instruction from senior faculty members who were themselves prescribing buprenorphine. Increasing the ability of the workforce to prescribe this medicine through an Accreditation Council for Graduate Medical Education (ACGME) mandate can only take us so far and will leave us with family physicians who are wavered to prescribe but do not do so, either from lack of appropriate clinical training, fear, or stigma. Effective role modeling by mentors is one of the few effective ways of moving early career family physicians from simply obtaining the DEA-X waiver to actually prescribing the medicine. Without a doubt, this will involve policy thrusts that find a way to increase the numbers of mid-and late-career family physicians who prescribe this medicine.

Peterson and his colleagues ${ }^{5}$ have illustrated clearly that, while Family Medicine is making great strides to address the opioid crisis in a thoughtful manner, work remains on multiple fronts. Policies to increase buprenorphine training in residency programs, decrease the amount of burdensome federal regulation associated with buprenorphine prescription itself, and to improve access to training for mid- and late-career family physicians are urgently needed to slow the rising tide of deaths due to opioid use disorder.

To see this article online, please go to: http://jabfm.org/content/ 33/1/4.full.

\section{References}

1. National Center for Health Statistics. NCHS Data Brief (Data Brief No. 329): Drug overdose deaths in the United States, 1999-2017. 2018. https://www. cdc.gov/nchs/data/databriefs/db329-h.pdf (Hyattsville, MD).

2. Pierce M, Bird SM, Hickman M, et al. Impact of treatment for opioid dependence on fatal drug-related poisoning: a national cohort study in England. Addiction 2015;111:298-308.

3. Hickman M, Steer C, Tilling K, et al. The impact of buprenorphine and methadone on mortality: a primary care cohort study in the United Kingdom. Addiction 2018;113:1461-76.

4. Lipari R, Park-Lee E, Van Horn S. American's need for and receipt of substance use treatment in 2015. Rockville, MD: Center for Behavioral Health Statistics and Quality, Substance Abuse and Mental Health Services Administration; 2016.

5. Peterson LE, Morgan ZJ, Eden AR. Early-career and graduating physicians more likely to prescribe Buprenorphine. J Am Board Fam Med 2020;1:7-8.

6. Provenzano AM. Caring for Ms. L.-Overcoming my fear of treating opioid use disorder. N Engl J Med 2018;378:600-1.

7. Rosenblatt RA, Andrilla CH, Catlin M, Larson EH. Geographic and specialty distribution of US physicians trained to treat opioid use disorder. Ann Fam Med 2015;13:23-6.

8. Coffa D, Snyder H. Opioid use disorder: medical treatment options. Am Fam Physician 2019;100: 416-25.

9. Fiscella K, Wakeman SE, Beletsky L. Buprenorphine deregulation and mainstreaming treatment for opioid use disorder: $\mathrm{X}$ the $\mathrm{X}$ waiver. JAMA Psychiatry 2019;76:229-30.

10. Suzuki J, et al. Preliminary survey of office-based opioid treatment practices and attitudes among psychiatrists never receiving buprenorphine training to those who received training during residency. Am J Addictions 2014;23:618-622.

11. Lopez G. America's doctors can beat the opioid epidemic. Here's how to get them on board. Vox Oct 31, 2018. Available from: http://www.vox.com/ science-and-health/2018/7/31/17398914/opioidepidemic-project-echo-new-mexico-addiction. 